\title{
Hygro-thermal implications of the aerogel-based façade insulation layer position and thickness
}

\author{
Samira Aien ${ }^{1}$, Ardeshir Mahdavi ${ }^{1}$ \\ ${ }^{1}$ Building Physics and Building Ecology, TU Wien, Vienna, Austria
}

\begin{abstract}
Application of insulation to existing facades can improve buildings' energy performance and reduce condensation risk. However, in case of historical buildings, the preservation of the façade's appearance represents a constraint regarding the choice of insulation method. In such cases, aerogel-based plaster may provide a solution. In this context, the present study investigated the effect of aerogel plaster position and thickness on the hygro-thermal performance of residential buildings using a simulation model. The results suggest that, with regard to the surface condensation risk, the position of aerogel plaster (outside versus inside) - but not so much its thickness - significantly influences the risk of condensation.
\end{abstract}

\section{Introduction}

High-energy demand of existing buildings motivates retrofit campaigns and raises issues regarding building envelope performance (Gabriele et al., 2017). Application of insulation to external walls can represent an effective measure (Xin et al., 2018). However, a considerable fraction of existing building facades in Europe must be protected in view of historical significance. Moreover, the risk of interstitial condensation resulting from improper thermal retrofit can lead to undesirable consequences (Ibrahim et al., 2014). In this regard, effective moisture control can reduce condensation risk and contribute to energy use reduction (Pacheco et al., 2016). Insulating plasterbased materials involving silica aerogels could represent a potential solution for thermal retrofit of facades, whose original appearance must be preserved (Schuss et al. 2017). The silica aerogel is a low weight and generally translucent, Nano porous material with very high porosity $(>90 \%)$ (Gabriele et al., 2017), Low density (about $3 \mathrm{~kg} . \mathrm{m}^{3}$ ) and low thermal conductivity (0.014 W.m ${ }^{-1}$. K ${ }^{-1}$ ) (Pacheco et al., 2016). Respective solutions must address both energy use reduction and moisture control via consideration of the characteristics and configuration of the insulating system (e.g., locations of insulation layers, insulation thickness) (Ozel, 2014; Stahl et al., 2012). Such solutions can be assessed proactively using appropriate software (Mundt Petersen et al., 2013).

For the purpose of the present contribution, a typical Austrian residential building was selected as a case study to investigate the effect of aerogel plaster position (specifically, inside versus outside) and thickness (from 3 to $10 \mathrm{~cm}$ ) on the thermal and hygrothermal performance by using a hygro-thermal simulation model.

One set of results pertains to the influence of insulation on energy use. We specifically considered variables pertaining to heating and cooling loads compared to the reference case (façade with conventional plaster).

A second set of result suggests that the position of aerogel plaster noticeably influences the condensation and mould growth risk in the winter period. Specifically, exterior positioning leads to a preferable performance.

In order to predict the hygro-thermal performance of buildings and the condensation damage potential, software solutions for the computation of moisture transfer in building components have been developed. For the purposes of the present contribution, a commercially available hygro-thermal simulation software was used. To increase the credibility of the simulation outcomes, the present effort benefited from a previous study that utilized monitored data from an actual implementation project to calibrate the hygrothermal simulation model (Schuss et al., 2017).

\section{Approach}

\section{The case study building}

To examine annual energy demand (HWB) as performance indicator, a typical multi-unit apartment building in the city Vienna, Austria was selected as a base case. Figure 1 shows the typical plan of this building. The building has two blocks ( $\mathrm{A}$ and $\mathrm{B}$ ) in six floors, connected via staircase and corridors (Figure 2). The attic space of block B and basement of block A are unheated. The building entails residential units with a total net heated space area of $1737 \mathrm{~m}^{2}$. The assumed data on the building's construction (see Table 1) were assumed based on its construction date (TABULA, 2018). The existing wall construction of the case study (with three layers including gypsum plaster, solid brick masonry and lime cement plaster), was assumed to be retrofitted by applying a solution encompassing the highly insulating Aerogel layer Fixit 222 (2018). Table 2 presents the assumed hygro-thermal characteristics of the component layers. 


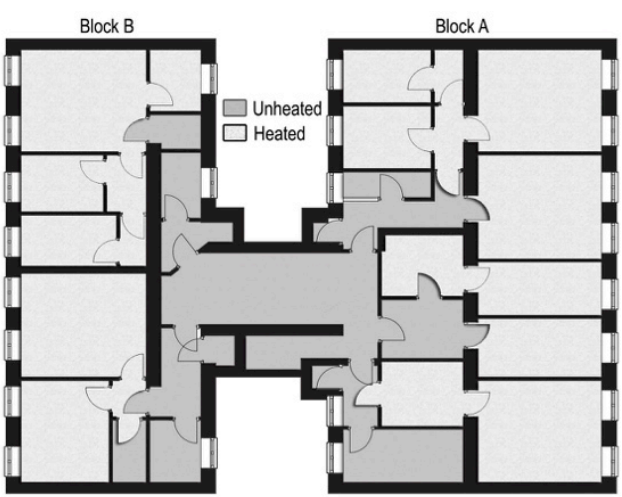

Figure 1: Plan and thermal zoning of the case study building model

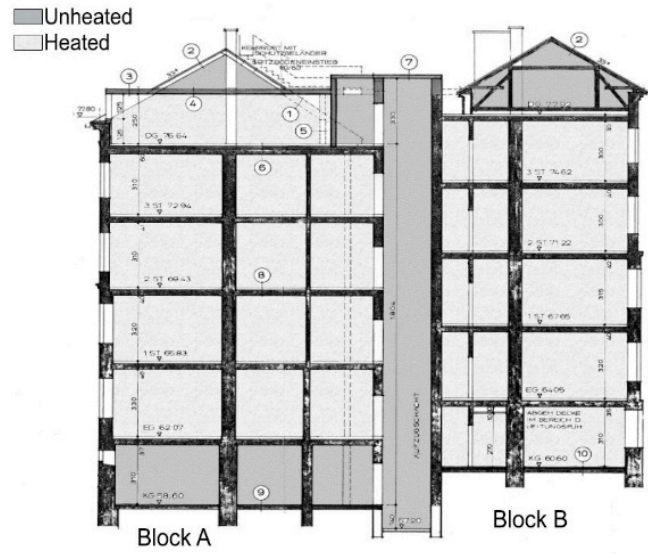

Figure 2: Section and thermal zoning of the case study building model

Table 1: Construction data on Austria building types

\begin{tabular}{|c|c|c|c|c|}
\hline Elements & Roof & Wall & Floor & Window \\
\hline Picture & प14 & 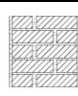 & 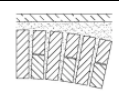 & \\
\hline $\begin{array}{l}\text { U-Value } \\
{\left[\mathbf{W} \cdot \mathbf{m}^{-2} \cdot \mathbf{k}^{-1}\right]}\end{array}$ & 0.80 & 1.10 & 0.71 & 2.20 \\
\hline Constru & $\begin{array}{l}\text { Wooden ceiling } \\
\text { with filling, } \\
\text { wooden planks }\end{array}$ & $\begin{array}{l}\text { Solid } \\
\text { brick }\end{array}$ & $\begin{array}{l}\text { Brick } \\
\text { vault } \\
\text { ceiling }\end{array}$ & $\begin{array}{l}\text { Single } \\
\text { glazing } \\
\text { box }\end{array}$ \\
\hline
\end{tabular}

\section{Simulation Scenarios}

Multiple retrofit solutions for external wall were defined based on insulation thickness $(3,5,7$, and 10 $\mathrm{cm}$ ) and position (inside vs. outside). To evaluate the hygro-thermal performance of retrofitted building model, eight scenarios were designed based on alternative configurations of thickness and position of insulation layer. These configurations were labelled as Scenario A1 to Scenario D2, as listed in Table 3. It should be noted that, general simulation settings (Table 4) and material properties (Table 2) were kept constant in the aforementioned configurations.
Table 2: Hygro-thermal properties of material of the building's external wall

\begin{tabular}{|l|c|c|c|c|c|}
\hline Properties & Unit & Aerogel & $\begin{array}{l}\text { Cement } \\
\text { Plaster }\end{array}$ & Brick & $\begin{array}{l}\text { Interior } \\
\text { plaster }\end{array}$ \\
\hline Layer thickness & $\mathrm{m}$ & $0.03-0.1$ & 0.03 & 0.40 & 0.02 \\
\hline Bulk density & $\mathrm{kg} \cdot \mathrm{m}^{-3}$ & 220 & 1900 & 1560 & 1721 \\
\hline Porosity & & 0.92 & 0.24 & 0.38 & 0.31 \\
\hline $\begin{array}{l}\text { Specific heat } \\
\text { capacity }\end{array}$ & $\mathrm{J} \cdot \mathrm{kg}^{-1} \cdot \mathrm{K}^{-1}$ & 1000 & 850 & 850 & 850 \\
\hline $\begin{array}{l}\text { Thermal } \\
\text { conductivity } \\
\text { (dry material at } \\
\text { 10 C) }\end{array}$ & $\mathrm{W} \cdot \mathrm{m}^{-1} \cdot \mathrm{K}^{-1}$ & 0.029 & 0.80 & 0.6 & 0.2 \\
\hline $\begin{array}{l}\text { Water vapor } \\
\text { diffusion } \\
\text { resistance } \\
\text { factor }\end{array}$ & - & 4 & 19 & 14.93 & 13 \\
\hline $\begin{array}{l}\text { Reference water } \\
\text { content (RH } \\
\text { 80\%) }\end{array}$ & $\mathrm{kg} \cdot \mathrm{m}^{-3}$ & 6.6 & 45 & 11.80 & 1.77 \\
\hline $\begin{array}{l}\text { Free water } \\
\text { saturation (RH } \\
\text { 100\%) }\end{array}$ & $\mathrm{kg} \cdot \mathrm{m}^{-3}$ & 213 & 210 & 368.9 & 264.2 \\
\hline $\begin{array}{l}\text { Water } \\
\text { absorption } \\
\text { coefficient }(\mathbf{A}- \\
\text { value) }\end{array}$ & $\mathrm{kg} \cdot \mathrm{m}^{-2} \cdot \mathrm{s}^{-0.5}$ & 0.0004 & 0.0333 & 0.58 & 0.30 \\
\hline $\begin{array}{l}\text { Moisture- } \\
\text { dependent } \\
\text { thermal } \\
\text { conductivity } \\
\text { supplement }\end{array}$ & $\% \cdot \mathrm{M}^{-1} \%$ & 0.5 & 8 & 8.51 & 3.23 \\
\hline
\end{tabular}

Table 3: Retrofit scenarios

\begin{tabular}{|c|c|c|}
\hline Scenarios & Aerogel Thickness (m) & Aerogel Position \\
\hline Base case & - & - \\
\hline A1 & 0.03 & Outside \\
\hline A2 & 0.03 & Inside \\
\hline B1 & 0.05 & Outside \\
\hline B2 & 0.05 & Inside \\
\hline C1 & 0.07 & Outside \\
\hline C2 & 0.07 & Inside \\
\hline D1 & 0.10 & Outside \\
\hline D2 & 0.10 & Inside \\
\hline
\end{tabular}

\section{Boundary conditions}

For the definition of outdoor conditions, the hourly weather data of outdoor climate was utilized for the city of Vienna, Austria. Indoor climate assumptions were derived in the program based on outdoor climate via standard EN15026 (2007). The initial condition at the start of the simulations were specified based on program's default values (temperature $20^{\circ} \mathrm{C}$ and relative humidity $80 \%$ ).

\section{Simulation tool}

The base simulation model is created according to current construction details, materials, and systems in the case regions. The purpose of creating a base model is to estimate the annual energy consumption of conventional construction practice for the case study project without retrofit. The building was modelled in 
Energy Plus v8.7.0 (2018). Equipment, occupancy and lighting schedule derived from the schedule's library of the program. The air change rate was assumed to be $0.5\left[\mathrm{~h}^{-1}\right]$. As the second step to evaluate effect of insulation position in the layer of construction on moisture transfer, the external wall construction was modelled in WUFI Pro v5.3 (2018). This tool enabled the simultaneous calculation of heat and moisture transport in one (WUFI PRO) and two (WUFI 2D) dimensions. Material properties, boundary conditions, as well as initial conditions were assumed to be identical in both programs. The other inputs and settings were defined base on calibrated simulation model in previous study (Aien et al., 2018) as per Table 4

Table 4: General settings and input for the WUFI model

\begin{tabular}{|c|c|c|c|}
\hline \multicolumn{2}{|c|}{ Setting and inputs } & Value & Unit \\
\hline \multirow{2}{*}{ Orientation } & Height & $\begin{array}{c}>10 \text { and } \\
<20\end{array}$ & $\mathrm{~m}$ \\
\hline & Inclination & 90 & {$\left[{ }^{\circ}\right]$} \\
\hline $\begin{array}{l}\text { Building } \\
\text { height- } \\
\text { driven rain } \\
\text { coefficient }\end{array}$ & $\begin{array}{l}\text { Rain load } \\
\text { (According to the } \\
\text { ASHRAE Standard } \\
160 \text { ) }\end{array}$ & $\begin{array}{c}\mathrm{FD}=1 \\
\mathrm{FE}=1.2\end{array}$ & - \\
\hline \multirow{7}{*}{$\begin{array}{l}\text { Surface } \\
\text { transfer } \\
\text { coefficient }\end{array}$} & $\begin{array}{l}\text { Thermal resistance } \\
\text { of exterior surface }\end{array}$ & 0.0588 & $\mathrm{~m}^{2} \cdot \mathrm{K} \cdot \mathrm{W}^{-1}$ \\
\hline & $\begin{array}{l}\text { Sd-value of exterior } \\
\text { surface }\end{array}$ & 0.2 & $\mathrm{~m}$ \\
\hline & $\begin{array}{l}\text { Short wave } \\
\text { radiation } \\
\text { absorptivity } \\
\end{array}$ & 0.4 & - \\
\hline & $\begin{array}{l}\text { Ground short wave } \\
\text { reflectivity }\end{array}$ & 0.2 & - \\
\hline & $\begin{array}{l}\text { Adhering fraction } \\
\text { of rain }\end{array}$ & $\begin{array}{c}\text { No } \\
\text { absorption }\end{array}$ & - \\
\hline & $\begin{array}{l}\text { Thermal resistance } \\
\text { of interior surface }\end{array}$ & 0.125 & $\mathrm{~m}^{2} \cdot \mathrm{K} \cdot \mathrm{W}^{-1}$ \\
\hline & $\begin{array}{l}\text { Sd-value of interior } \\
\text { surface }\end{array}$ & 0.1 & $\mathrm{~m}$ \\
\hline
\end{tabular}

\section{Performance criteria}

Two types of criteria were considered in the framework of this retrofitted project by applying aerogel plaster:

(a) Building energy (heating and cooling) demand as a function of insulation thickness

(b) Moisture transfer and condensation risk as a function of the position of the insulation layer

It is well known that the heat transmission load declines with increasing insulation thickness, however, the reduction rate of heating loads as the thickness increases, will be a significant challenge to achieve the optimize thickness. From this aspect, the rate of changing heating and cooling loads, which derived from energy plus simulation tool, were investigated. To assess hygro- thermal behaviour of the wall structure, condensation risk and mould growth potential, aforementioned scenarios (Table 2) were evaluated using WUFI simulation program. In this purpose, the hourly total water content values of different construction configurations (Table 2) over a period of three years (offered by the software) were analysed. Their initial water content corresponds to software settings at $20^{\circ} \mathrm{C}$ and $80 \%$ relative humidity.

Moreover, condensation risk assessment in middle of the wall structure was conducted by comparing the brick layer temperature and respective dew point temperature over a period of three years for all scenarios.

\section{Summary of the previous calibration effort}

The hygro-thermal analysis of the aforementioned construction options (see Tables 2 and 3) were as such not accompanied by experimental measurements. However, respective simulation runs benefited from a previous study whereby the results from the deployed tool (WUFI) could be compared to long-term measured data, leading to insights concerning tool calibration potential. This calibration effort (summarized below), while not directly transportable to the present study, nonetheless provided us with a higher level of confidence as to the ranges and reliability of the present contribution's outcome. The previous contribution effort entailed the results of a case study on the predictive performance of hygro-thermal simulation of an existing wall construction. A set of sensors measured the temperature and relative humidity levels. The measured data was used to define the model's initial conditions to evaluate the validity of the simulation models and potential model calibrations. The simulation results of the hygro-thermal performance were compared with the corresponding measured values at each time step. The results of the simulation scenarios (see Table 5) suggested that the predictive potency of the simulation model can considerably improve by adjusting the input variables based on measurements (Aien e al., 2018). The initial model represents the case when the measurement is not available. The above-mentioned boundary conditions were considered as default values in this model. The Scenarios $01-04$ were defined base on importing the measured initial conditions, measured indoor conditions, and measured outdoor climate and twodimensional modelling, respectively. Note that all setting of the previous scenarios were kept constant in all configurations.

Figures 5 and 6 present the coefficient of determination $\left(\mathrm{R}^{2}\right)$ value of relative humidity and temperature of all scenarios in each layer. The model in scenario 3 generated outputs with acceptable $\mathrm{R}^{2}$ values, for both relative humidity (more than 0.8 ) and temperature (more than 0.94). There was a significant improvement after feeding in the actual indoor conditions (Scenario 2), in three layers of Aerogel, brick, and interior plaster. Moreover, feeding the local outdoor climate (Scenario 3) improved the result of relative humidity and temperature in the exterior plaster layer. Detailed geometry modelling of hollow 
brick, namely two-dimensional modelling, improved the relative humidity predictions.

Table 5: Calibration Scenarios

\begin{tabular}{|l|l|l|l|l|}
\hline Scenarios & WUFI & $\begin{array}{l}\text { Initial } \\
\text { condition }\end{array}$ & $\begin{array}{l}\text { Indoor } \\
\text { condition }\end{array}$ & $\begin{array}{l}\text { Outdoor } \\
\text { climate }\end{array}$ \\
\hline $\begin{array}{l}\text { Initial } \\
\text { model }\end{array}$ & PRO & Constant & EN15026 & Map file \\
\hline $\mathbf{0 1}$ & PRO & Measured & EN15026 & Map file \\
\hline $\mathbf{0 2}$ & PRO & Measured & Measured & Map file \\
\hline $\mathbf{0 3}$ & PRO & Measured & Measured & Measured \\
\hline $\mathbf{0 4}$ & 2D & Measured & Measured & Measured \\
\hline
\end{tabular}

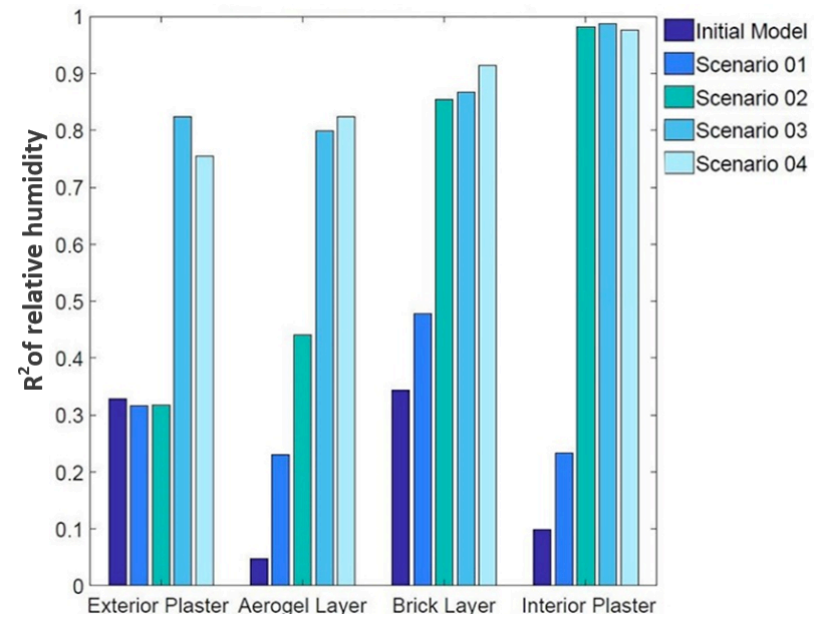

Figure 5: R2 of relative humidity of all scenarios in each node

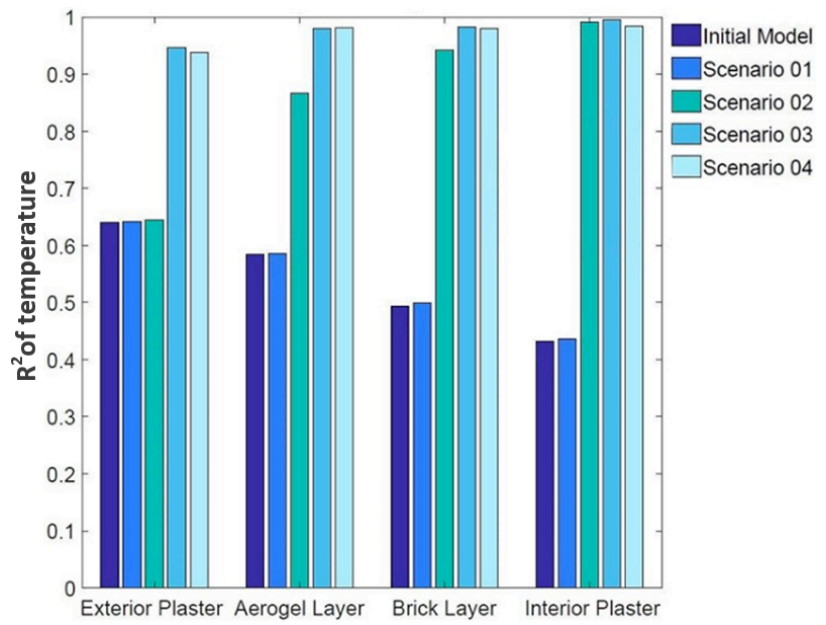

Figure 6: R2 of temperature of all scenarios in each node.

\section{Result and discussion}

The simulated annual heating demand for the base case amounts to $115 \mathrm{kWh} \cdot \mathrm{m}^{-2}$, which is similar to the TABULA project value (109 kWh.m $\left.{ }^{-2}\right)$ given for a building of this category (multifamily apartment) and age. Figure 7 illustrates the monthly heating loads (months without heating load are excluded) for the base case model and various insulation thickness values (scenarios A1, B1, C1, and D1). As it can be seen, in January and December (peak demand of heating load), scenario A1 (applying $3 \mathrm{~cm}$ thickness of insulation plaster) leads to a $21 \%$ reduction of heating load, while the rate of decrease drops down to 6,4 , and $2 \%$ as the insulation thickness increases in scenario B1 $(5 \mathrm{~cm}), \mathrm{C} 1(7 \mathrm{~cm})$, and D1 $(10 \mathrm{~cm})$.

Annual heating and cooling reduction for various insulation thickness values (scenarios A1, B1, C1, and D1) are compared to the base model in Table 6 . Whereas the heating load reduction potential is noteworthy (23 - 36\%), cooling loads are only slightly reduced with increased insulation thickness (scenario A1-D1).

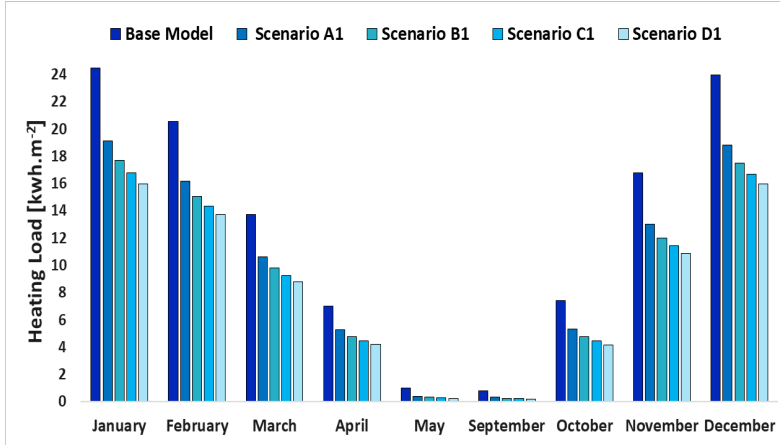

Figure 7: Comparison of the simulated scenarios (see Table 3) in terms of the resulting monthly heating loads (months without heating load are excluded)

Table 6: Annual heating and cooling reduction (as compared to the base model) for various insulation thickness values (scenarios A1, B1, C1, and D1)

\begin{tabular}{|l|c|c|c|c|}
\hline Scenarios & A1 & B1 & C1 & D1 \\
\hline Heating load & $23 \%$ & $29 \%$ & $33 \%$ & $36 \%$ \\
\hline Cooling load & $3 \%$ & $2 \%$ & $1 \%$ & $-0.5 \%$ \\
\hline
\end{tabular}

Figure 8 shows the total amount of water content for different construction configurations over a period of three years. Thereby, the influence of the assumed initial conditions on the early phase of the simulation period can be seen. The results suggest that the total water content values of the wall structures were significantly higher when the insulation layer is positioned inside (scenario A2-D2) rather than outside (scenario A1-D1), especially in the winter period. 


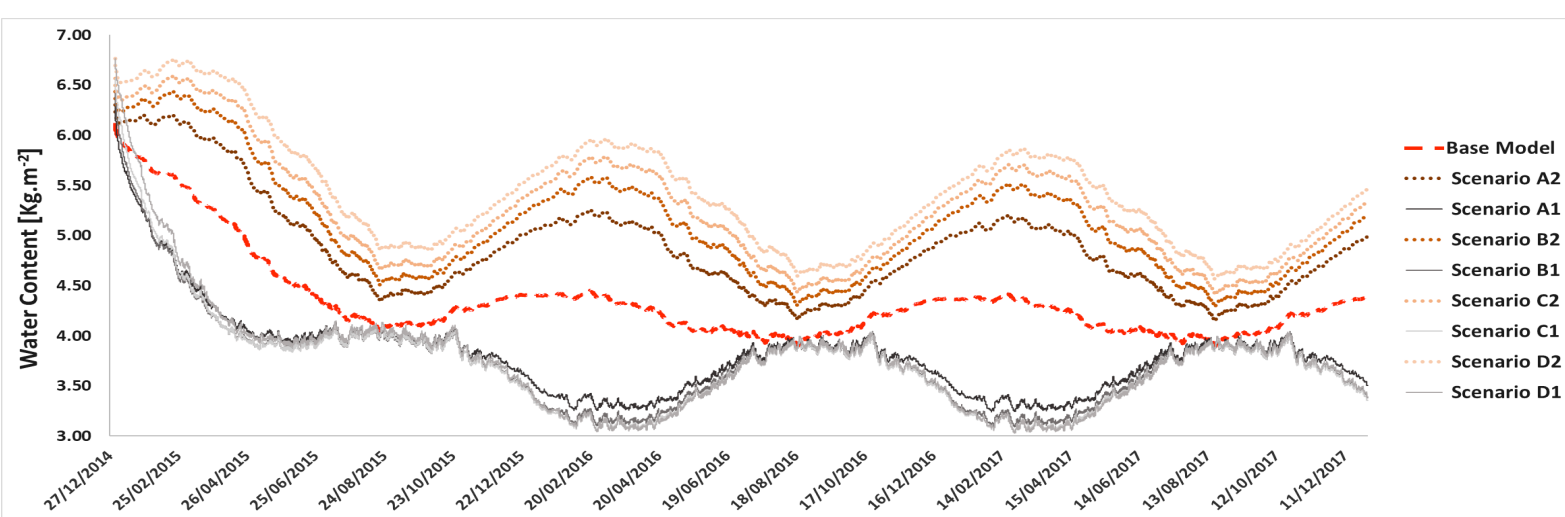

Figure 8: Simulated whole construction water content over a period of three years for different configurations

Figures 9 to 11 show the brick layer temperatures and corresponding dew point temperatures for the base model, scenario B2 (insulation positioned inside), and B1 (insulation positioned outside). As it can be seen from these figures, in case of B1, condensation is unlikely. However, it can occur in case of B2, and to a lesser extent, in the base case.

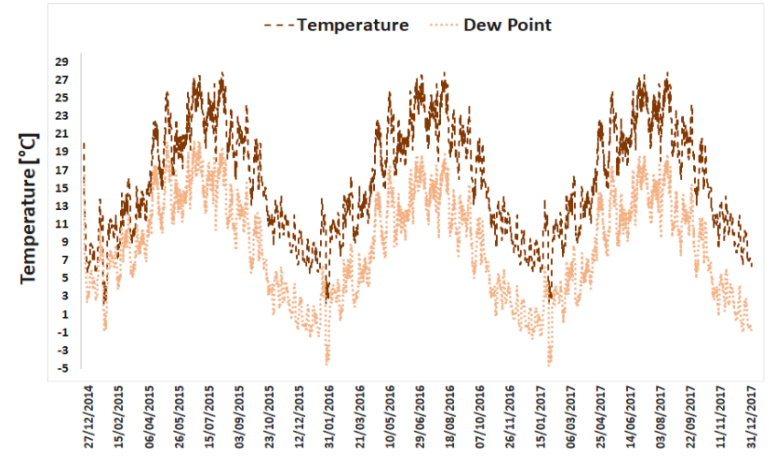

Figure 9: Simulated brick layer temperature and respective dew point temperature over a period of three years for the base model

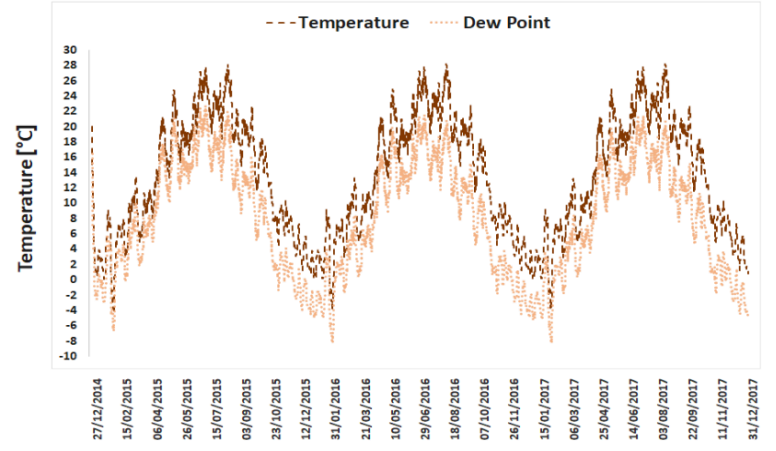

Figure 10: Simulated brick layer temperature and respective dew point temperature over a period of three years for inside position of Aerogel

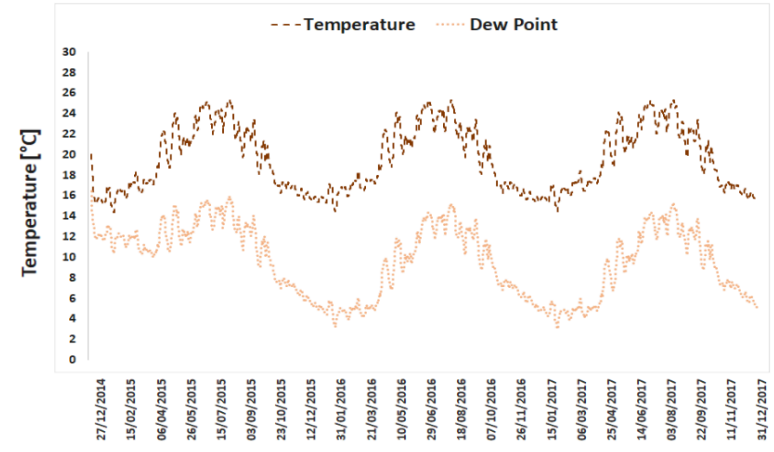

Figure 11: Simulated brick layer temperature and respective dew point temperature over a period of three years for outside position of Aerogel

\section{Conclusion}

This contribution entailed the results of a case study on the predictive performance of hygro-thermal simulations of an existing wall retrofitted with an Aerogel-based plaster layer. The study benefited from a previous empirically based model calibration for improving simulation tool's predictive performance. The study documented an insulating rendering based on silica-aerogels to be added to the existing external walls without changing the overall appearance. Different insulated wall configurations were studied to compare their hygro-thermal performance. Results show that interior thermal insulation systems can lead to moisture problems and condensation risk. The base model, uninsulated wall, displayed higher heat loss rates as compared to the insulated ones. Adding aerogel-based rendering on the exterior surface of wall can considerably reduce heat losses (roughly $23 \%$ to $36 \%$, depending on the layer thickness) and involves little risk of moisture problems. 


\section{Reference}

Aien, S. Taheri, M. Schuss, M and Mahdavi A. (2018). A Comparison of Measured and Simulated HygroThermal Performance Indicators' Values: The Case of a Retrofitted Wall Construction. Proceedings from BauSIM 2018 conference. Karlsruhe (Germany), Sep 2018.

EN 15026. (2007). Hygro- thermal performance of building components and building elements: Assessment of moisture transfer by numerical simulation. ISBN: 9780580547416.

Energy Plus. (2018). Energy Plus TM Documentation Getting Started with Energy Plus Basic Concepts Manual - Essential Information You Need about Running.

Fixit. (2018), http://www.fixit.ch/Home/Produkte/Restaurierungs-und-Sanierungsprodukte/. Last accessed on 20.04.2018.

Gabriele, M. Ghazi Wakili, K. Stahl, Th. Brunner, S. Galliano, R. Monticelli, C. Aliprandi, S. Zanelli, A. and Elesawy, A. (2017). Development of a SuperInsulating, Aerogel-Based Textile Wallpaper for the Indoor Energy Retrofit of Existing Residential Buildings. Procedia Engineering 180 (May): 1139 -49 .

Ibrahim, M. Etienne, W. Pascal, H. Patrick, A. and Hebert, S. (2014). Hygro- thermal Performance of Exterior Walls Covered with Aerogel-Based Insulating Rendering. Energy and Buildings 84: 241-51.

Kürekci Nuri, Al. Ağra, Ö. and Emanet, Ö. (2017). Development of a Super-Insulating, Aerogel-Based Textile Wallpaper for the Indoor Energy Retrofit of Existing Residential Buildings. Procedia Engineering 180: 1139-49.

Mundt Petersen, S. and Harderup, L. (2013). Validation of a One-Dimensinal Transient Heat and Moisture Calculation Tool under Real Conditions. Proceedings from thermal Performance of the Exterior Envelopes of Whole Buildings XII international conference. USA (Florida), Des 2013.

Ozel, M. (2014). Effect of Insulation Location on Dynamic Heat-Transfer Characteristics of Building External Walls and Optimization of Insulation Thickness. Energy and Buildings 72: 288-95.

Pacheco, T. Cinzia, B. Siva, K. Claes-Göran, G. and Volodymyr, I. (2016). Nano Biotech Based Materials for Energy Building Efficiency. Switzerland.

Schuss, M. Mahdavi, A. Pont, U. Sustr, C. Aien, S. Ghazi Wakili, K. and Stahl, Th. (2017). Strukturierte Aerogelputze. In Bauphysik-Kalender 2017, 153-75. Ernst\&Sohn. Architektur und technische Wissenschaften. Berlin (Germany).
Stahl, Th. Brunner, S. Zimmermann, M. and Ghazi Wakili, K. (2012). Thermo-Hygric Properties of a Newly Developed Aerogel Based Insulation Rendering for Both Exterior and Interior Applications. Energy and Buildings 44: 114-117.

TABULA. (2018). Http:// Webtool.BuildingTypology.Eu/\#bm. Last accessed, on 10.01.2019.

WUFI. (2018). Frauenhofer Institute for Building Physics, Holzkirchen. Information on http://www.WUFI.de/index e.html. Last accessed on 20.04.2018.

Xin, L. Chenchen, W.Chuanzhi, L. Guohuni, F. Zekai, Y. and Zonghan, L. (2018). Effect of the EnergySaving Retrofit on the Existing Residential Buidings in the Typical City in Northern China. Energy and Buildings 177:154-172. 